\title{
DEVIATORIC RESPONSE OF AN ARMOUR-GRADE ALUMINIUM ALLOY
}

\author{
G. J. Appleby-Thomas ${ }^{1}$, P. J. Hazell ${ }^{1}$, J. Millett ${ }^{2}$, and N. K. Bourne ${ }^{2}$ \\ ${ }^{I}$ Cranfield Defence and Security, Cranfield University, Shrivenham, Swindon, SN6 8LA, UK \\ ${ }^{2} A W E$, Aldermarston, Reading, Berkshire, RG7 4PR, UK
}

\begin{abstract}
Aluminium alloys such as $5083 \mathrm{H} 32$ are established light-weight armour materials. As such, the shock response of these materials is of great importance. The shear strength of a material under shock loading provides an insight into its ballistic performance. In this investigation embedded manganin stress gauges have been employed to measure both the longitudinal and lateral components of stress during plate-impact experiments over a range of impact stresses. In turn, these results were used to determine the shear strength and to investigate the time dependence of lateral stress behind the shock front to give an indication of material response.
\end{abstract}

Keywords: Al 5083, plate-impact, lateral gauge, armour.

PACS: 47.40.-x, 47.40.Nm., 62.20.M-.

\section{INTRODUCTION}

Low density and high strengths have led to the widespread adoption of aluminium alloys for armour applications. Consequently, knowledge of the high strain-rate behaviour of such alloys is advantageous. Various authors have investigated the shock response of different grades of aluminium. For example, the dynamic response of Al 6061 over the stress range 4-22 GPa was investigated by Huang and Asay [1], who showed that the strength of Al 6061 increased with shock loading at the same rate, independent of processing history. Similar results were found in a study of three FCC metals, where Millett et al. [2] investigated strengthening phenomenon in $\mathrm{Al}$ 6082-T6. Further, by incorporating lateral gauges into the targets and noting the behaviour of lateral stress following shock arrival, it was suggested that little additional work hardening occurred. This was thought to be due to the presence of dispersed inter-metallic particles which acted to suppress the formation of dislocation cells.
The wrought alloy Al 5083 combines low density with high strength (due to a high $\mathrm{Mg}$ content) and resistance to corrosion [1,3]. Work on Al 5083 has centred on ballistic and relatively low strain-rate testing, either to validate armour concepts or to provide data for model evaluation. E.g. Børvik et al. [3] investigated the penetration mechanisms in Al 5083-H116 plate. This data was used along with other similar experimental work [4] to calibrate a Johnson Cook constitutive model by Clausen et al. [5] for strain-rates $\leq 1,500 \mathrm{~s}^{-1}$. Despite its use as an armour material, relatively little information exists in the literature on the dynamic response of $\mathrm{Al} 5083$ at higher strain-rates. Boteler and Dandekar [6] conducted plate-impact experiments on two armour-grade tempers of Al5083 - H131 (strain-hardened) and H32 (strainhardened/partially annealed) at impact stresses of 1.5-8.1 GPa. Hugoniot equations-of-state were established and Hugoniot elastic limits (HEL's) of 0.57 (H131) and 0.44 (H32) GPa determined from the recorded shock histories. Elastic-plastic responses involving (i) an initial elastic rise up to 
the HEL; (ii) elastic-plastic work hardening, before; (iii) a plastic rise to the Hugoniot stress, were noted for both tempers. Despite this work, while studies have been conducted on Al 6082-T6 [2], no investigation of lateral stress (and therefore shear strength) either at or following shock arrival has been undertaken in $\mathrm{Al}$ 5083. In this paper plate-impact experiments involving embedded lateral manganin stress gauges are used to measure the lateral stress response of $\mathrm{Al} 5083(\mathrm{H} 32)$ at strain-rates $>5,000 \mathrm{~s}^{-1}$. In addition, by comparison to measured longitudinal impact stresses and the established $U_{S}-u_{P}$ Hugoniot for Al 5083 H32 [6], the variation in shear strength behind the shock is investigated [7].

\section{EXPERIMENTAL PROCEDURE}

\section{Elastic properties}

Sound speeds were measured ultrasonically using a Panametrics 5077PR pulse receiver in the pulse-echo configuration using appropriate Panametrics 5.0 MHz transducers as: $c_{L}=6.32 \pm$ $0.10 \mathrm{~mm} / \mu \mathrm{s}$, and; $c_{S}=3.11 \pm 0.10 \mathrm{~mm} / \mu \mathrm{s}$. The density was taken as $2.668 \pm 0.004 \mathrm{~g} / \mathrm{cm}^{3}$ [6]. From these results, elastic properties were calculated as: $c_{0}=5.19 \pm 0.10 \mathrm{~mm} / \mu \mathrm{s}$ (in good agreement with the value of $c_{0}=5.36 \pm 0.02$ $\mathrm{mm} / \mu \mathrm{s}$ for $\mathrm{Al} 5083$ from [6]) and $v=0.34 \pm 0.02$.

\section{Plate-impact experiments}

Plate-impact experiments [7] were conducted at impact velocities of $80-960 \mathrm{~m} / \mathrm{s}$ using a $\varnothing 50 \mathrm{~mm}$ bore single-stage gas-gun [8]. The target, adhered to a mounting ring, was placed at the end of a sacrificial barrel extension which was attached to the muzzle of the gun according to the arrangement shown in Fig. 1. All surfaces perpendicular to the impact axis were finished to a surface roughness of $<5 \mu \mathrm{m}$. Impact velocity was measured by

TABLE 1. Key experimental parameters/results.

\begin{tabular}{cccc}
\hline $\begin{array}{c}\mathbf{v}_{\text {impact }} \\
(\mathbf{m} / \mathbf{s})\end{array}$ & Flyer & $\boldsymbol{\sigma}_{\mathbf{Y}}(\mathbf{G P a})$ & $\boldsymbol{\sigma}_{\mathbf{X}}(\mathbf{G P a})$ \\
\hline 200 & $10 \mathrm{~mm} / \mathrm{Dural}$ & 1.00 & $1.43[6]$ \\
438 & $10 \mathrm{~mm} / \mathrm{Dural}$ & 2.42 & 3.06 \\
450 & $10 \mathrm{~mm} / \mathrm{Cu}$ & 3.87 & $4.75[6]$ \\
657 & $10 \mathrm{~mm} / \mathrm{Cu}$ & 6.35 & 7.85 \\
\hline
\end{tabular}

sequentially shorting a series of pins, while data recording was started by shorting two trigger pins.

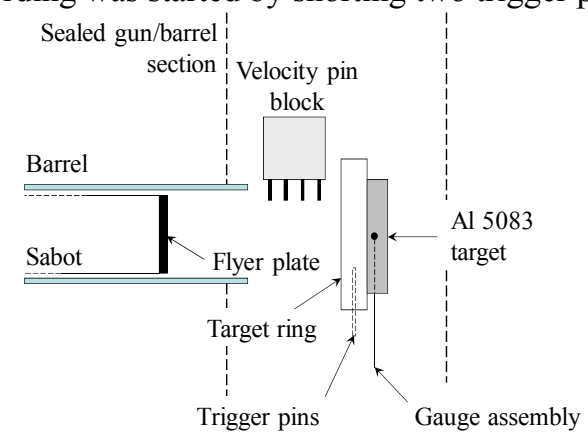

Figure 1. Lateral gauge plate-impact experimental setup.

Target plates contained a centrally located embedded lateral manganin gauge (type J2M-SS580SF-025, manufactured by Vishay MicroMeasurements), situated $2 \mathrm{~mm}$ from the impact face and insulated from the surrounding Al by 25 $\mu \mathrm{m}$ thick Mylar. A modified form of the impedance matching technique was used for lateral gauge interpretation. This approach assumed that the strain in a thin (foil) laterally embedded gauge was equivalent to that of the surrounding material [9]. Both the elastic-plastic [10] and pressure response below the HEL [11] were also accounted for. Hugoniot stress data was established using longitudinal gauges (Vishay Micro-Measurements \& SR-4 type LM-SS-125CH-048) in both rear surface (at $438 \mathrm{~m} / \mathrm{s}$ ) and longitudinal-only configurations [7]. Calibration was in line with [12], with interpretation following the impedance matching technique [7]. Examples of these configurations for the lateral and rear surface gauges are shown in Fig 2. All elements were bonded using slow curing Loctite 0151 HYSOL® Epoxi-Patch ${ }^{\circledR}$ Adhesive.

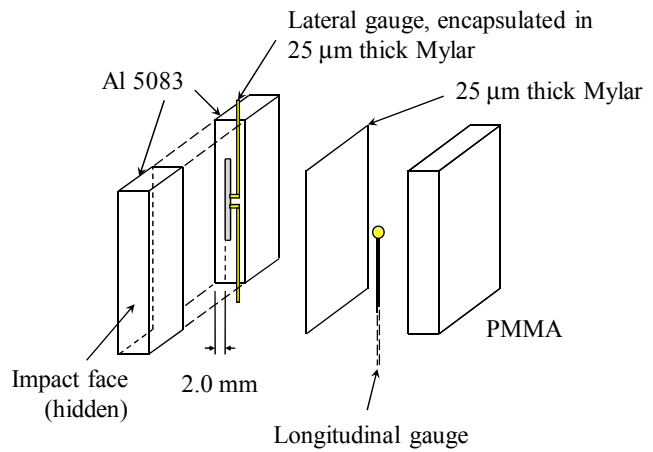

Figure 2. Typical target package geometries. 


\section{RESULTS AND DISCUSSION}

A total of four lateral shots using either Dural or $\mathrm{Cu}$ flyers were undertaken according to the configuration shown in Fig. 1. Complimentary Hugoniot data is also included, from either: (i) for the $438 \mathrm{~m} / \mathrm{s}$ shot, an included rear-surface gauge modified according to the approach outlined in [7]; (ii) longitudinal gauge-only shots, or; (iii) for the 200 and $450 \mathrm{~m} / \mathrm{s}$ shots, from [6] based on a knowledge of the impact conditions. The four unsmoothed lateral gauge traces recorded (temporally separated by $0.25 \mu \mathrm{s}$ ) are shown in Fig. 3 .

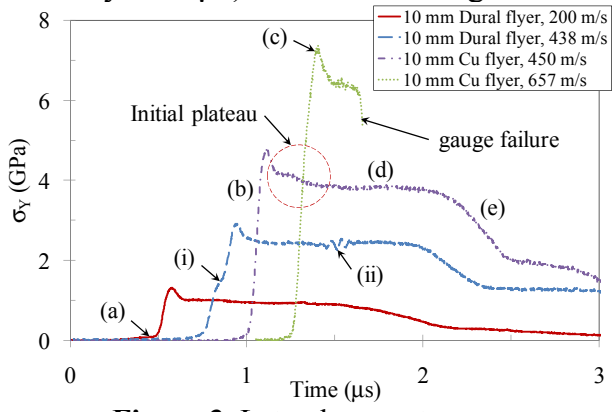

Figure 3. Lateral gauge traces.

Various common features on the un-processed gauge traces presented in Fig. 3 are discussed in Table 2. In addition, two slightly anomalous features were apparent on the $438 \mathrm{~m} / \mathrm{s}$. A kink in the rise at (i) was noted to possess a frequency similar to that of the overshoot at (c), and was consequently attributed to ringing within the gauge package. At (ii) noise was linked to the initial response of the rear-surface longitudinal gauge. Gauge failure following the start of the initial plateau on the $657 \mathrm{~m} / \mathrm{s}$ shot is also apparent, while a notable initial plateau in lateral stress is highlighted on the $450 \mathrm{~m} / \mathrm{s}$ shot.

Shear strength, $\tau$, is related to the longitudinal and lateral stresses by [7],

$$
2 \tau=\sigma_{X}-\sigma_{Y}
$$

Applying Equation (1) to the data presented in Table 1, the variation of shear strength with (calculated) impact stress - assuming a constant Hugoniot stress - is shown in Fig. 4. Errors were consistently smaller than the data points and are therefore not included for clarity. A predicted elastic response based on Equation (2), with $v=$ 0.34 , is also included for comparison [7].

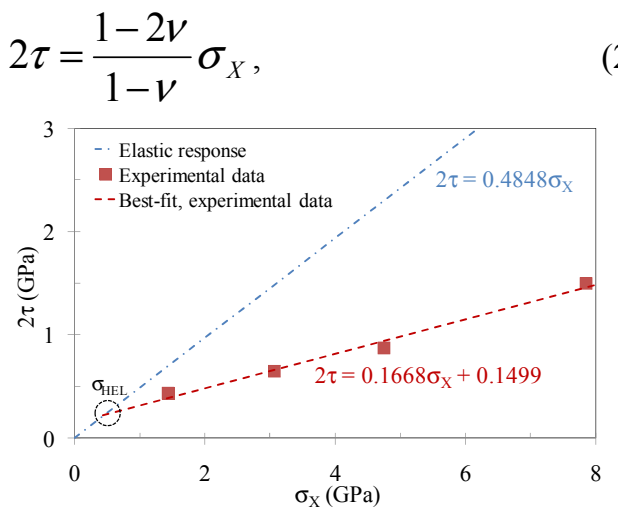

Figure 4. Variation of shear strength with impact stress.

The measured shear strengths lie below the elastic response, confirming that shock loading leads to plastic deformation. Deviation from the elastic response represents the onset of plastic deformation. Consequently, the intercept with the measured shear strength data should represent the HEL of the shocked Al 5083 (H32). From Fig. 4, this approach gives $\sigma_{H E L}=0.47 \mathrm{GPa}$, in good agreement with the value of $0.44 \pm 0.02 \mathrm{GPa}$ measured for $\mathrm{Al} 5083 \mathrm{H} 32$ in [6]. This good correlation with the literature, despite the assumption of some Hugoniot stress data from [6], gives confidence in the observed lateral stress/shear strength behaviour of $\mathrm{Al} 5083$.

TABLE 2. Key features of lateral traces presented in Fig. 3.

\section{Point Description}

(a) Initial ramp - as the gradient was independent of impact stress, this was attributed to a gauge response.

(b) A rise to a peak lateral stress.

(c) An initial overshoot - a low duration of c. 100 ns meant this was attributed to establishment of stress equilibrium in the gauge encapsulation, rather than a material response [3].

(d) An approximately constant lateral stress (with a slight gradient in some cases).

(e) A two-stage (elastic and plastic) unloading, following arrival of release waves from the rear of the flyer. 
Assuming a constant Hugoniot stress, Equation (1) implies that lateral gauge responses can be used to interrogate changes in shear strength behind the shock [2]. While still controversial $[7,13]$, this approach is considered here. Some structure is apparent in the traces in Fig. 3. Following the initial gauge overshoot, a plateau occurs followed by a decrease to a constant lateral stress which is then maintained until release. This initial feature (highlighted for the $450 \mathrm{~m} / \mathrm{s}$ shot in Fig. 3) becomes more pronounced at higher impact velocities. From Equation (1), this decrease in lateral stress might be interpreted as strengthening behind the shock [2]. However, these phenomena have a short duration (typically c.200 ns) and, as well as being in close proximity to the initial overshoot, in all cases are followed by a rapidly evolving constant lateral stress. Consequently, it appears there is insufficient information to suggest that strengthening occurs behind the shock. A similar conclusion was reached for the similar material Al 6082-T6 in [2]; attributed to the presence of dispersed fine intermetallic particles acting to suppress the formation of dislocation cells (and therefore hardening) post-shock.

\section{CONCLUSIONS}

The evolution of lateral stress in Al 5083 (H32) has been studied using plate-impact experiments. Embedded lateral manganin gauges have been used to show that plastic deformation is occurring. The intercept between (measured) plastic and (calculated) elastic shear strength curves has yielded an HEL of c. $0.47 \mathrm{GPa}$ - in good agreement with results found elsewhere. In addition, while a small initial plateau was noted, the lack of a long-range gradient behind the shock in recorded lateral gauge traces suggested little strengthening behind the shock in this temper of $\mathrm{Al}$ 5083. In line with analysis of Al 6082-T6 reported in the literature, this is likely due to the presence of dispersed intermetallic particles acting to prevent the formation of ordered dislocation cells.

\section{ACKNOWLEDGEMENTS}

The authors are grateful to Mr Gary Cooper and $\mathrm{Mr}$ Andrew Roberts for experimental support. British Crown Copyright - MOD/2009.

\section{REFERENCES}

1. Huang, H. and Asay, J. R., "Compressive strength measurements in aluminum for shock compression over the stress range 4-22 GPa”, J. Appl. Phys 98, 033525, 2005.

2. Millett, J. C. F., Whiteman, G. and Bourne, N. K., "Lateral stress and shear strength behind the shock front in three face centred cubic materials", J. Appl. Phys. 105, 033515, 2009.

3. Børvik, T., Clausen, A. H., Hopperstad, O. S. and Magnus, L., "Perforation of AA50083-H116 aluminium plates with conical-nose steel projectiles - experimental study", Int. J. Impact Engng. 30, 367, 2004.

4. Grytten, F., Børvik, T., Hopperstad, O. S. and Langseth, M., "Low velocity perforation of AA5083-H116 aluminium plates", Int. J. Impact Engng. 36, 597, 2009.

5. Clausen, A. H., Børvik, T., Hopperstad, O. S. and Benallal, A., "Flow and fracture characteristics of aluminium alloy AA5083-H116 as function of strain rate, temperature and triaxiality", Mater. Sci. Engng. A 364, 260, 2004.

6. Boteler, J. M. and Dandekar, D. P., "Dynamic response of two strain-hardened aluminum alloys", J. Appl. Phys. 100, 054902, 2006.

7. Appleby-Thomas, G. J., Hazell, P. J., Stennett, C., Helaar, K. and Diederen, A. M., "Shock propagation in a cemented tungsten carbide", J. Appl. Phys. 105, 064916, 2009.

8. Bourne, N. K., "A $50 \mathrm{~mm}$ bore gas gun for dynamic loading of materials and structures", Meas. Sci. \& Tech. 14, 273, 2003.

9. Rosenberg, Z. and Partom, Y., "Lateral stress measurement in shock-loaded targets with transverse piezoresistance gauges", J. Appl. Phys. 58(8), 3072, 1985.

10. Rosenberg, Z. and Brar, N. S., "The influence of the elasto-plastic properties of piezoresistance gauges on their loading-unloading characteristics as lateral shock wave transducers", J. Appl. Phys. 77(4), 1443, 1995.

11. Millett, J. C. F., Bourne, N. K. and Rosenburg, Z., "On the analysis of transverse stress gauge data from shock loading experiments", J. Phys. D: Appl. Phys. 29, 2466, 1996.

12. Rosenberg, Z., Yaziv D. and Partom, Y., "Calibration of foil-like manganin gauges in planar shock wave experiments", J. Appl. Phys. 51(7), 3702, 1980.

13. Winter, R. E. and Harris, E. J., "Simulations of embedded lateral stress gauge profiles in shocked targets”, J. Phys. D: Appl. Phys. 41, 035503, 2008. 